\title{
LABORATORY EXPERIMENT ON GENERATION OF ANAEROBIC GAS AND SCUM FROM ORGANIC SLUDGE IN URBAN RIVERS
}

\author{
SHIN MIURA ${ }^{1}$, TADAHARU ISHIKAWA ${ }^{2}$ \& TETSUO HOTTA $^{1}$ \\ ${ }^{1}$ CTI Engineering Co., Ltd., Tokyo, Japan \\ ${ }^{2}$ Tokyo Institute of Technology, Japan
}

\begin{abstract}
Although the area served by sewers in Tokyo's wards has reached $100 \%, 80 \%$ of this is combined sewer systems that were built before 1980, and when there is a storm runoff, organic sludge is discharged into rivers. Scums with malodor often appear in the brackish water reach of urban rivers due to the buoyancy caused by anaerobic gas produced in organic sludge deposition. In this study, a series of laboratory experiments were carried out using organic sludge collected from combined sewer systems to investigate the generation of anaerobic gas and scum. Water temperature, salinity, sediment ignition loss, and amount of sedimentation were controlled, and the gas components were analysed. The range of experimental conditions was determined from field observations of the Nomi River, which flows through the southern part of the Tokyo ward area. Gas analyses indicated that two-thirds of the anaerobic gas is methane and that hydrogen sulphide increases under high-salinity conditions. Based on the measurements of the rate of gas generation, a practical empirical formula was prepared that includes the effect of control factors. Observations of scum generation in the experiments indicated that generation time is inversely proportional to gas generation rate, and the amount of sediment formed is proportional to the initial volume of sediment accumulation.
\end{abstract}

Keywords: urban river estuary, organic sludge, scum with malodor, anaerobic gas emission.

\section{INTRODUCTION}

While the area served by sewers in the Tokyo ward area has reached $100 \%, 80 \%$ of this is combined sewer systems that were built before 1980 [1]. In rainy weather, organic sludge that have accumulated in pipes and culverts, along with fine-grained soil and sand are discharged into small and medium-sized urban rivers. The water quality in these rivers temporarily deteriorates due to these organic pollutants [2]. In particular, in downstream brackish-water reaches in which flow is stagnant, deposited organic sludge floats to the surface after rainfall as scum giving off a stench and causes environmental problems in surrounding areas.

Based on site investigations in past research [3]-[5], the mechanism for scum generation is thought to be as follows (Fig. 1):

(a) Rain water collected by the combined sewer system washes out the organic sludge: The rainwater collected by the combined sewer system washes out the organic sludge deposited in pipes during intense rain run-off.

(b) Deposition of sludge: Sludge settles in the deep downstream reach due to flow velocity reduction.

(c) Stratification and Anoxic: The bottom river water layer becomes anaerobic due to the oxygen consumption of the organic pollutants and density stratification.

(d) Generation of anaerobic gases: Anaerobic gases such as methane are generated within the deposited organic sludge.

(e) Surfacing of scum: Organic pollutants rise to the surface as scum with malodor due to buoyancy caused by the anaerobic gases. 


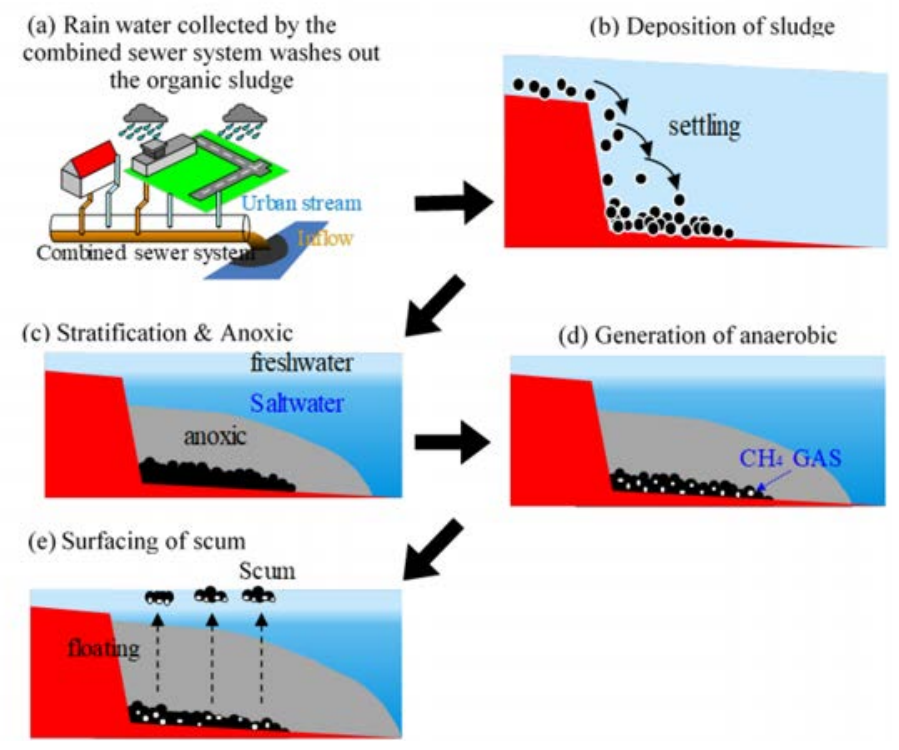

Figure 1: The mechanism for scum generation.

Hamada et al. [6] indicated that scum generated in enclosed bays is organic mud that sticks to itself due to the content of highly sticky oils and fats. In addition, Hotta et al. [7] suggested an empirical formula for the rate of anaerobic gas generation from experiments and field observations in canals, and Ushikubo et al. [8] performed gas generation rate experiments using samples collected in coastal areas. However, the organic matter content (ignition loss) of bottom mud used in this previous research was $30 \%$ or less, which is much lower than in post-rainfall sediment in urban rivers.

In addition, anaerobic gas production rates determined in research on reducing greenhouse gas emissions vary widely in studies of methane gas output from marsh areas and the like [9]. However, these were results of measurements of emissions in a variety of fields, and the effect on water temperature, salinity, and other such influencing factors is not quantitatively understood.

Therefore, in this research, we first gained an understanding of the water quality conditions in which scum forms based on records of observations that Ota City office performed on the Nomi River. In addition, basic laboratory experiments were carried out that simulated anaerobic gas generation and the rise of scum from organic sludge collected in the combined sewer system of the catchment basin to garner a quantitative understanding of its characteristics and generation rates.

\section{FIELD OBSERVATIONS}

\subsection{Research location}

Fig. 2(a) shows the Nomi River catchment basin, and (b) shows a maximum depth of riverbed lateral profile. The water depth gradually increases from the brackish-water upper reaches near $5.7 \mathrm{KP}$ to $3.8 \mathrm{KP}$, and the water depth is nearly constant from $3.8 \mathrm{KP}$ to the 
mouth of the river. Because of this, the organic sludge that flows out during rainfall is thought to readily deposit in the vicinity of $3.8 \mathrm{KP}$. In fact, although the section in which scum floats ranges from 5.0 KP to $3.0 \mathrm{KP}$, river patrols observed floating scum in the neighbourhood of $3.8 \mathrm{KP}$.

\subsection{Method}

The Ota City Office Environmental Measures Division installed an automatic water quality measuring instrument (Horiba W-22XD) at a site at $3.8 \mathrm{KP}$ on the Nomi River, which flows within the ward. It also recorded and classified the state of scum generation from visual observations during river patrols carried out once daily on weekdays as shown in Table 1.

\subsection{Results}

Fig. 3(a) shows the daily rainfall and daily maximum hourly rain fall at the AMeDAS observation station in Setagaya City. Figs 3(b) and (c) show continuous observation records on a $50 \mathrm{~cm}$ river bed at $3.8 \mathrm{KP}$ from April to October 2015, and Fig. 3(d) shows the state of scum generation. In (d), red dotted vertical lines were added on days in which a medium amount of scum developed (no "high amounts" of scum were generated in this time period). In many cases, rain had fallen 1 to 2 days prior to scum generation, and this rainfall is marked in red in (a). In addition, rainfall events after which scum did not develop within 2 days are marked in blue, and blue dotted vertical lines were added 1 day after such rains. From these data the following trends can be seen.

The continuous observation record shows that at $3.8 \mathrm{KP}$ the bottom layer salinity in normal periods is 10 to $30 \%$. The bottom layer water DO was almost zero, and the ORP was $-330 \mathrm{mV}$ or lower, which is the level at which anaerobic gases are generated by methanogenic bacteria. However, when there is flooding, the salinity declines somewhat, and

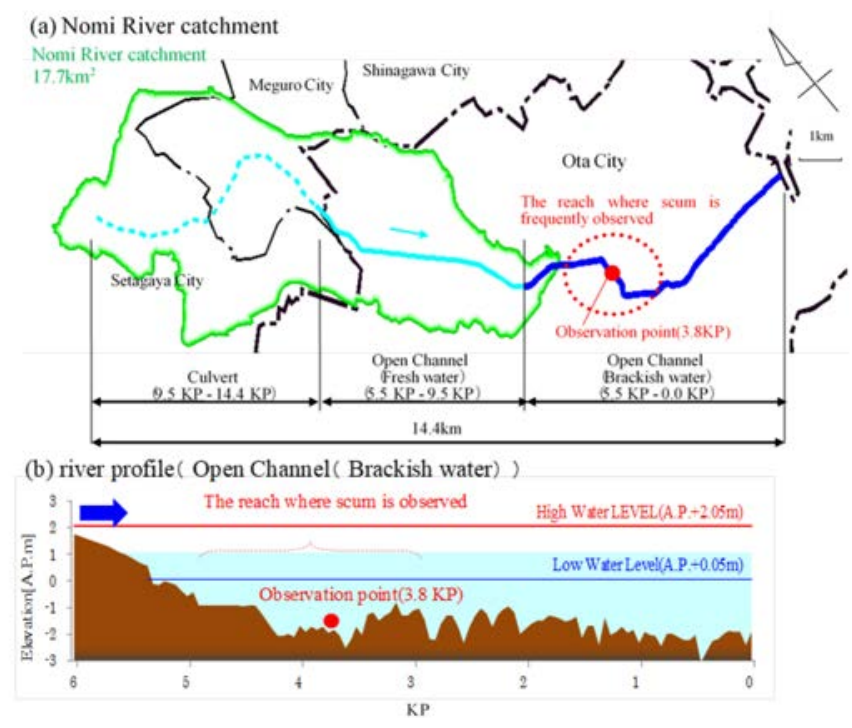

Figure 2: (a) Nomi River catchment basin; (b) River-bed lateral profile. 
Table 1: Classification of the amount of scum.

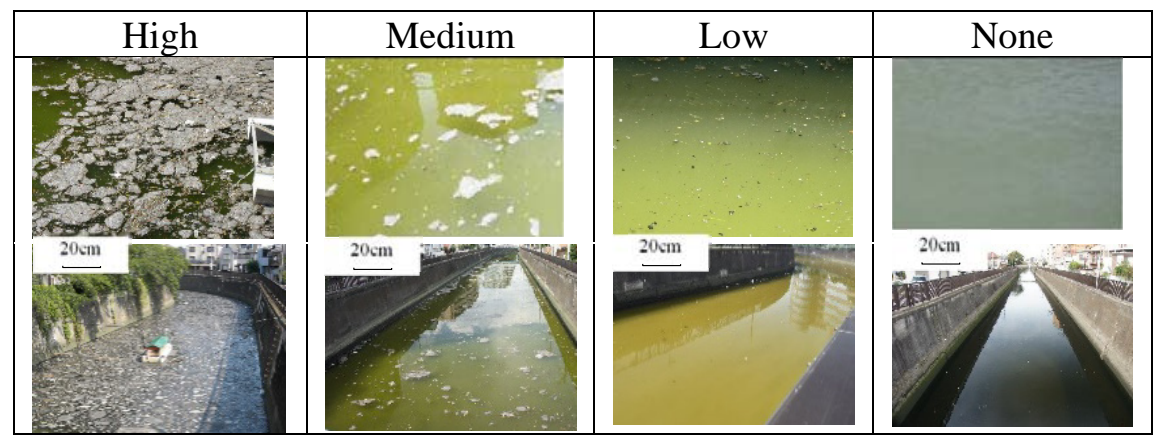

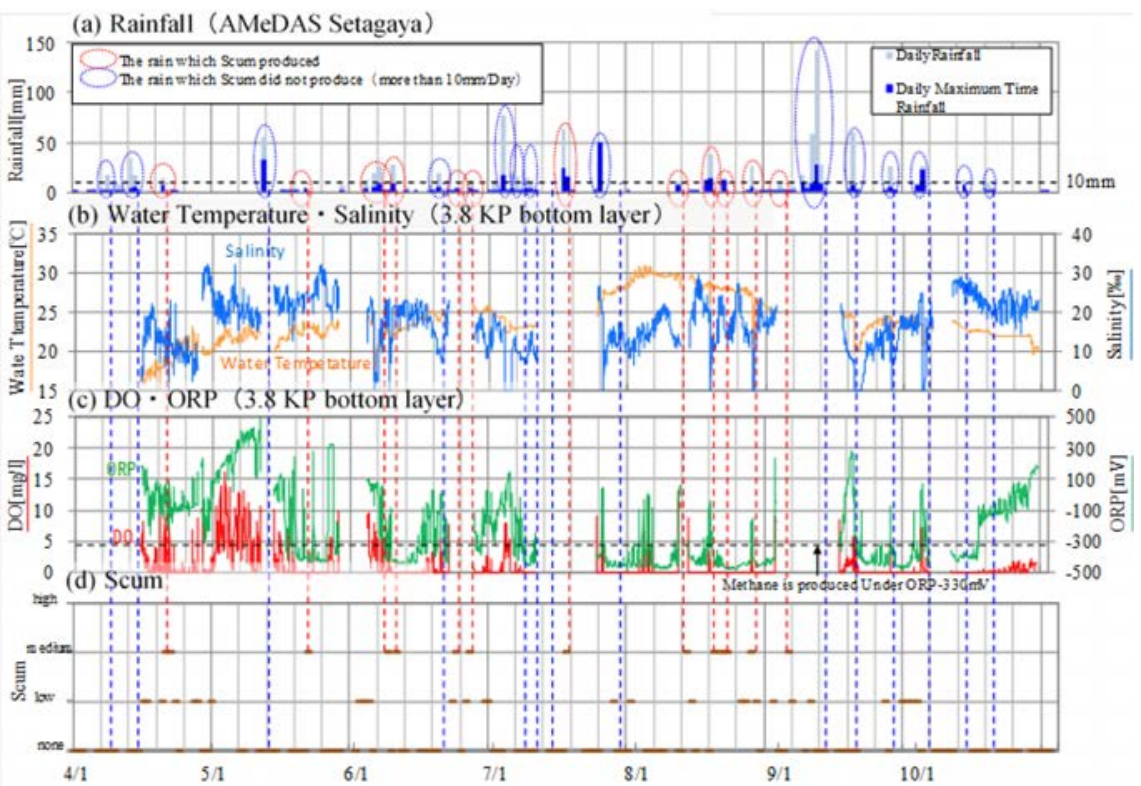

Figure 3: Results of field observations.

DO increases slightly. Correspondingly, ORP does increase, but then frequently falls to -330 $\mathrm{mV}$ or less 1 to 2 days after small rainfalls (daily amounts of $50 \mathrm{~mm}$ or less).

Medium-level amounts of scum generation frequently occur 1 to 2 days after a relatively small rainfall of $10 \mathrm{~mm}$ or more. Because the lag time for flood flow to arrive at the Nomi River is about $1 \mathrm{~h}$, this 1- to 2-day time difference is mainly thought to be the time required to develop sufficient buoyancy, resulting from gas generation within sludge after its deposition. In addition, the frequency of scum generation increases in the summer (June to August) and decreases in the spring and autumn even with the same level of rainfall. Seasonal differences in water temperature are thought to play a role in this. On the other hand, there are many cases in which scum does not develop after daily rainfall amounts of $50 \mathrm{~mm}$ or more. The reason for this is believed to be that organic sludge deposition is more difficult 
due to increased flow velocity, so no sufficiently buoyant sludge layer develops that could generate anaerobic gases. In addition, the salinity in May and October is frequently $20 \%$ or higher, and it is also possible that methane formation is inhibited by high salinity, so scum does not readily develop.

Basic experiments were carried out related to anaerobic gas and scum generation on sedimentary sludge collected from within the sewer system in the Nomi River catchment basin, taking into consideration the actual conditions above.

\section{LABORATORY EXPERIMENTS}

\subsection{Experimental method}

\subsubsection{Experimental apparatus}

A fixed amount of organic sludge and salinity-adjusted river water was poured into a $45 \mathrm{~mm}$ inner diameter, $250 \mathrm{~mm}$ high syringe and stirred, and the salinity within the syringe was measured. Next, a piston was inserted, and after discharging air from the injection hole, the syringe was blocked closed and left to stand upright with the piston side up in a thermostatic chamber to track changes inside the syringe (Fig. 4).

\subsubsection{Test samples}

Sediment from under manholes was collected in two places in the middle of the Nomi River catchment basin drainage district. Table 2 presents the results of the analysis of these samples. It can be seen that the samples had a large amount of organic content, were slightly acidic, and had become anaerobic. In addition, electric conductivity was about the same as for fresh water. These samples were used in experiments untreated.

\subsubsection{Experimental conditions}

From the site conditions described in 2, experiments were carried out varying the four factors presented in Table 3 . A $5 \mathrm{~cm}$ buoyant sludge layer, $25^{\circ} \mathrm{C}$ water temperature, $10 \%$ salinity, and $70 \%$ loss on ignition were considered to be standard conditions. To investigate the influence of each factor, each factor was varied in the range shown in the right column. However, because the buoyant sludge layer thickness changes due to consolidation, the values in the chart are just guidelines, and the final result was adjusted according to the sludge input per unit area $\left(\mathrm{mg} / \mathrm{cm}^{2}\right)$. The water temperature was controlled by a temperature setting on the thermostatic chamber, and the salinity was adjusted by diluting sea water collected at the mouth of the Nomi River. In addition, the time to scum generation at the site was taken into account, and the test period was set to 2.5 days $(60 \mathrm{~h})$. Note that because of the limitations of the experimental equipment, measurements of DO and ORP in the water column could not be carried out. However, because the height of the experimental water column was about $1 / 50$ of the site water depth (approximately $3 \mathrm{~m}$ ), the anaerobic gas in the syringe was thought to have developed in an hour or less.

\subsubsection{Items to be measured and analysed}

A camera was installed laterally, and conditions within the syringe were photographed every $10 \mathrm{~min}$. The buoyant sludge layer thickness $\left(H_{\text {sed }}\right)$, the height of the column of water $\left(H_{\text {liq }}\right)$, the scum thickness $\left(H_{\text {scum }}\right)$, and the height of gas $\left(H_{\text {gas }}\right)$ were measured. The frictional resistance of the piston was confirmed to be very small (0.02 atm or less) in preliminary testing. In addition, the gases generated in 3 cases of differing salinity (with other factors at 


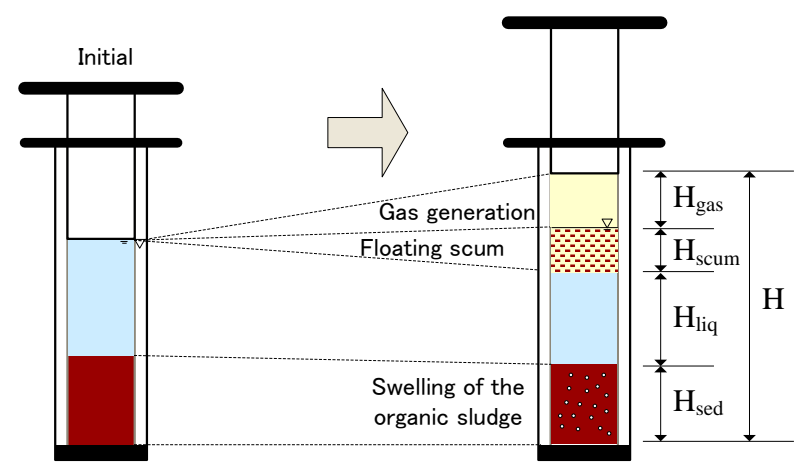

Figure 4: Experimental apparatus.

Table 2: Organic sludge samples.

\begin{tabular}{|c|c|c|c|c|c|}
\hline & $\begin{array}{c}\text { COD } \\
{[\mathrm{mg} / \mathrm{g}-\mathrm{dry}]}\end{array}$ & $\begin{array}{c}\text { Ignition loss } \\
{[\%]}\end{array}$ & $\begin{array}{c}\mathrm{pH} \\
{[-]}\end{array}$ & $\begin{array}{c}\text { ORP } \\
{[\mathrm{mV}]}\end{array}$ & $\begin{array}{c}\mathrm{EC} \\
{[\mathrm{mS} / \mathrm{cm}]}\end{array}$ \\
\hline Sample 1 & 286 & 70 & 6.64 & -123 & 0.37 \\
\hline Sample 2 & 275 & 79 & 6.71 & -68 & 0.22 \\
\hline
\end{tabular}

Table 3: Experimental conditions.

\begin{tabular}{|c|c|c|}
\hline & Standard condition & Range \\
\hline \hline Mud thickness & $5 \mathrm{~cm}$ & $2.2-8.1 \mathrm{~cm}$ \\
\hline Water temperature & $25^{\circ} \mathrm{C}$ & $15-30^{\circ} \mathrm{C}$ \\
\hline Salinity & 10 & $0-30$ \\
\hline Ignition loss & $70 \%$ & $70 \%, 79 \%$ \\
\hline
\end{tabular}

standard condition) were analysed for methane $\left(\mathrm{CH}_{4}\right)$ and carbon dioxide $\left(\mathrm{CO}_{2}\right)$ content by TCD (Thermal Conductivity Detector) and for hydrogen sulfide $\left(\mathrm{H}_{2} \mathrm{~S}\right)$ content by FPD (Flame Photometric Detector).

\subsection{Results}

Fig. 5 shows the changes within the syringe for standard conditions using sample 1. From the start of the test to $t=2$ hours, the buoyant sludge layer contracted slightly because of consolidation. At $\mathrm{t}=2$ to 3 hours, the piston started to rise as the sludge expanded. That is, it is thought that gas was generated in the sludge layer, and voids increased. At $t=3$ hours, twothirds of the sludge layer separated to become scum and rose to the bottom surface of the piston. This is thought to be because more buoyancy was created by fine bubbles generated in the sludge layer. At $t=6 \mathrm{~h}$, the rate of rise of the piston having reached a constant rate. It is thought that gas generation rate had reached steady state at this point. From $\mathrm{t}=12 \mathrm{~h}$ onward, a gas layer emerged between the scum and the bottom of the piston, and a free water surface formed. In conjunction with this, the scum gradually settled, and the sludge layer grew 
thicker. This is mainly thought to be because the fine bubbles within the scum coalesced and escaped upward. In addition, fine bubbles rising from the sludge layer were observed visually. Once the scum settled, it did not float again.

In all test cases, much the same course was seen as described above, so the average rate of rise of the piston from $\mathrm{t}=12 \mathrm{~h}$ to $60 \mathrm{~h}$, in which the piston rise was stable, was taken to be the gas generation rate per unit area. Changes in the gas generation rate caused by changing the test conditions were clarified and resolved below.

\section{DISCUSSION}

\subsection{Changes in gas generation rate with varied sludge input}

Fig. 6 presents gas generation rates when only sludge input was varied. From this it can be understood that the amount of gas generated is by and large proportional to the sludge input. That is, it is inferred that the generation of anaerobic gas takes place roughly uniformly in the entire buoyant sludge layer.

The relationship in the figure is approximated by the following equation, where $P_{0}$ : anaerobic gas generation rate at standard conditions $\left[\mathrm{cm}^{3 N} / \mathrm{cm}^{2} /\right.$ day], and $W$ : sludge input per unit area [mg-dry $\left./ \mathrm{cm}^{2}\right]$ :

$$
P_{0}=0.048 W
$$

\begin{tabular}{|c|c|c|c|c|c|}
\hline $\begin{array}{c}0 \text { hour } \\
\text { (start) }\end{array}$ & $\begin{array}{c}2 \text { hours } \\
\text { (consolidation) }\end{array}$ & $\begin{array}{c}3 \text { hours } \\
\text { (swelling) }\end{array}$ & $\begin{array}{c}5 \text { hours (floating } \\
\text { scum) }\end{array}$ & $\begin{array}{c}30 \text { hours } \\
\text { (increasing gas) }\end{array}$ & $\begin{array}{c}60 \text { hours (scum } \\
\text { disappearance) }\end{array}$ \\
\hline$\vdots$ & $\vdots$ & $\vdots$ & $\vdots$ & $\vdots$ \\
$\vdots$ & $\vdots$ & $\vdots$ & $\vdots$ & $\vdots$ & $\vdots$ \\
$\vdots$ & $\vdots$ & $\vdots$ & $\vdots$ & $\vdots$ & $\vdots$ \\
\hline
\end{tabular}

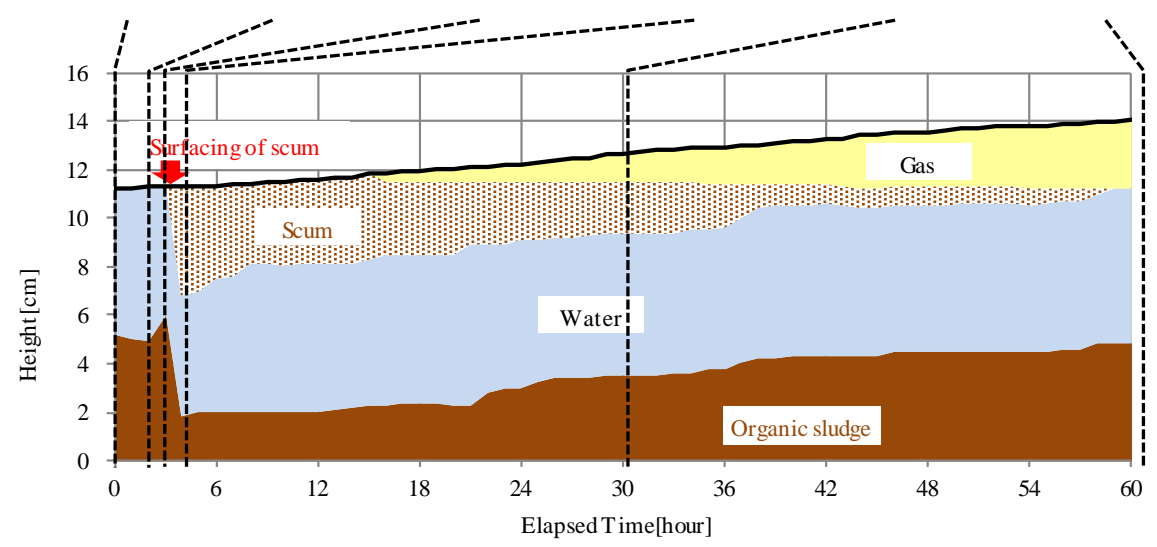

Figure 5: Changes within the syringe (standard case). 
Incidentally, Hotta et al. [7] assumed from field observations in canals that the anaerobic gas generation rate and buoyant sludge layer thickness generally had a proportional relationship, and while similar to the results of this research, the proportionality coefficient is different. This point is considered more later on.

\subsection{Changes in gas generation rate with varying water temperatures}

Fig. 7 presents the results of experiments carried out when only the water temperature was varied, taking $\theta_{T}$ to be the ratio of change from standard conditions $\left(25^{\circ} \mathrm{C}\right)$.

The rate of anaerobic gas generation is sensitive to water temperature, and there is a fourfold or greater difference between $20^{\circ} \mathrm{C}$ and $30^{\circ} \mathrm{C}$. In addition, at $10^{\circ} \mathrm{C}$ and below, almost no gas is generated. One can argue that the fact that scum mainly develops in the summertime is due to this temperature dependence. In biogas plant experiments [10], a temperature dependence was exhibited, however, the difference between $20^{\circ} \mathrm{C}$ and $30^{\circ} \mathrm{C}$ was just under two-fold, and the effect was small compared to these experimental results. These facts indicate that temperature dependence differs with experimental materials and environmental conditions and suggest the need to confirm gas generation rates depending on the conditions of the intended field. These experimental results can be approximated by the following equation where $\theta_{T}$ : temperature correction factor, and $T$ : water temperature $\left[{ }^{\circ} \mathrm{C}\right]$ :

$$
\theta_{T}=0.0058(T-10)^{1.9}
$$

\subsection{Changes in gas generation rate with varying salinity}

Fig. 8 presents the results of experiments carried out in which only the salinity varied, taking $\theta_{S}$ to be the ratio of change from standard conditions (salinity 10\%).

Gas generation rate decreases rapidly with increased salinity, and when salinity exceeds $25 \%$, the rate drops to almost zero. The reason for this is thought to be that with an increase in sulfide ions, the activity of sulfate-reducing bacteria that produce $\mathrm{H}_{2} \mathrm{~S}$ dominates that of methanogenic bacteria that produce $\mathrm{CH}_{4}$, and the solubility of $\mathrm{H}_{2} \mathrm{~S}$ is much higher than that of $\mathrm{CH}_{4}$ (80 times greater at $20^{\circ} \mathrm{C}$ ). Consequently, it is believed that the relatively small

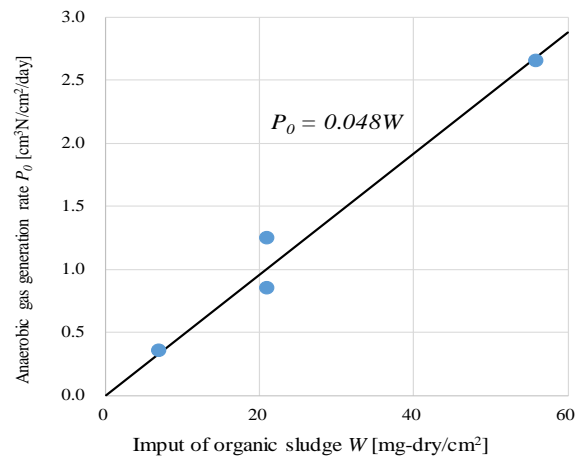

Figure 6: Relationship of anaerobic Figure 7: Relationship of anaerobic gas gas generation rate to input.

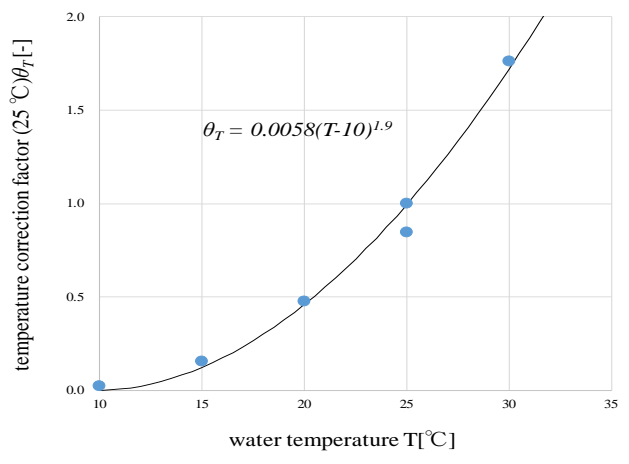
generation rate to water temperature. 
amount of scum generated in the summer and autumn of 2015 as shown in Fig. 2 is related to both low water temperature and the bottom layer of water being high in salinity.

These experimental results can be approximated by the following equation, where $\theta_{s}$ : salinity correction factor, and S: salinity [\%]:

$$
\theta_{s}=-0.08 S+1.8
$$

Hanna et al. [9] arranged the amounts of methane gas generated in a large number of lakes and marshes. While the amount of methane generated was shown to be smaller when salinity was high, their definition of typical salinity and their method for measuring the methane generation rate in the various lakes and marshes was not standardized, so this remains a qualitative discussion.

\subsection{Changes in gas generation rate as loss on ignition of bottom sediment varies}

The rate of anaerobic gas generation is thought to be highly related to the amount of source organic material (ignition loss). Fig. 9 presents the results of these experiments and the field observations of Hotta et al. [7], in which the average value of the experiments in samples having $70 \%$ loss on ignition were treated as the standard. It can be seen that the increase in gas generation rate relative to standard conditions $\theta_{I L}$ is mainly linear with respect to loss on ignition.

These results are approximated by the following equation where $\theta_{I L}$ : ignition loss correction factor, and $I L$ : ignition loss [\%]:

$$
\theta_{I L}=0.014 I L
$$

\subsection{Components of anaerobic gas}

Table 4 presents the components in the gas generated. A dash in the table indicates a component that was not analysed. The bottom row lists examples of reports from anaerobic fermentation of livestock excreta, edible oil residue, and the like at 10 biogas plant facilities [10] (referred to subsequently as biogas) for comparison. Approximately two-thirds of the gas generated in these experiments is $\mathrm{CH}_{4}$, which is about the same as biogas. Conversely, this gas contains less carbon dioxide than biogas. The reason for this is thought to be that, perhaps in addition to the difference in material to be decomposed, the difference in fermentation times may have an effect (20 days in biogas plants, 2.5 days in these experiments). Interestingly, when salinity reaches $20 \%, \mathrm{H}_{2} \mathrm{~S}$ exceeds $\mathrm{CO}_{2}$. Because $\mathrm{H}_{2} \mathrm{~S}$ is extremely poisonous, its effect on the human body and aquatic organisms even at minute amounts cannot be ignored.

\subsection{Suitability of empirical formulas}

From the results of eqns (2)-(5), the anaerobic gas generation rate $P_{a}\left[\mathrm{~cm}^{3 \mathrm{~N}} / \mathrm{cm}^{2} /\right.$ day $]$ can be expressed by the following equation. Here, $P_{0}$ is the gas generation rate at standard conditions in eqn (1), and $\theta$ is the correction factor for each influencing effect determined by eqns (2), (3), and (4). Fig. 10 shows the agreement of the above equation and the experimental results.

$$
P_{a}=\theta_{T} \theta_{S} \theta_{I L} P_{0}
$$




\subsection{Scum generation characteristics}

As shown in Fig. 5, when the buoyancy associated with gas generation exceeds a threshold value, the organic sludge floats to the surface as scum. The relationship of the gas generation

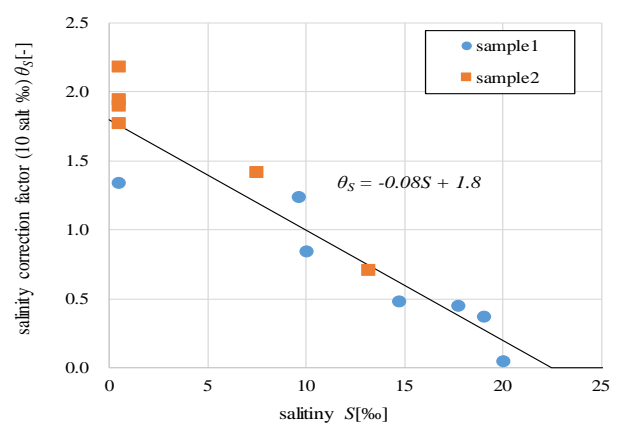

Figure 8: Relationship of anaerobic gas generation rate to salinity.

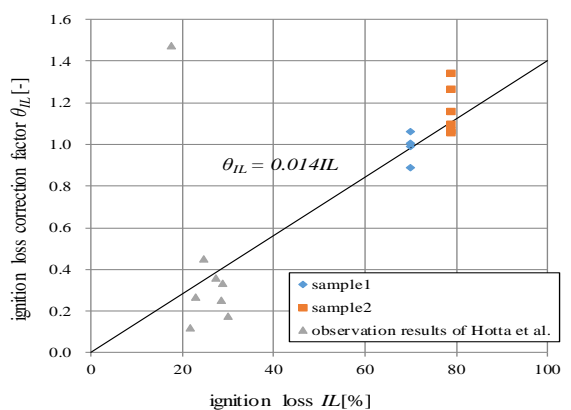

Figure 9: Relationship of anaerobic gas generation rate to loss on ignition.

Table 4: Components of anaerobic gas.

\begin{tabular}{|c|c|c|c|c|c|}
\hline & $\mathrm{CH}_{4}$ & $\mathrm{CO}_{2}$ & $\mathrm{~N}_{2}$ & $\mathrm{H}_{2} \mathrm{~S}$ & $\mathrm{O}_{2}$ \\
\hline \hline Salinity 0 & 66.3 & 11.7 & - & 0.02 & - \\
\hline Salinity 10 & 64.7 & 7.4 & - & 1.02 & - \\
\hline Salinity 20 & 62.0 & 4.8 & - & 5.96 & - \\
\hline Biogas & $48-65$ & $31-42$ & $3-16$ & - & $0-4.3$ \\
\hline
\end{tabular}

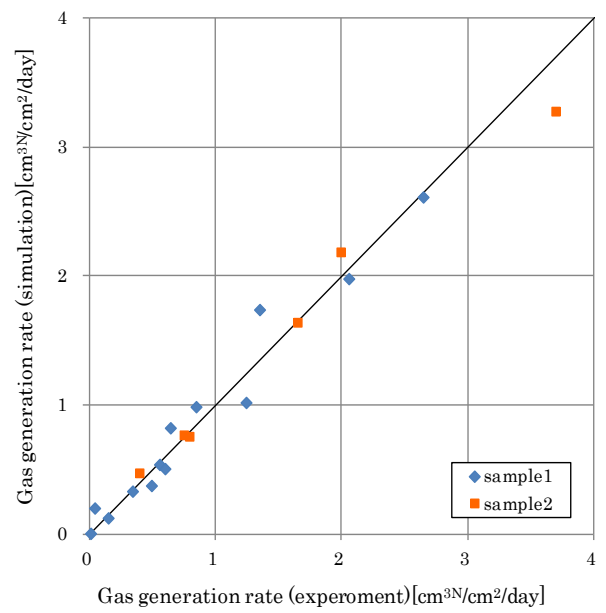

Figure 10: Relation of empirical formula to experimental results. 
rate and the time from test start to scum generation is plotted in Fig. 11. Although there is a lot of scatter in the data, there is an inversely proportional trend. It is considered that scum develops when the total amount of anaerobic gas generated exceeds the gas retention capacity of the sludge, so it is necessary to consider the gas retention capacity of the sludge in regard to sludge rise.

In addition, the relationship of the risen scum thickness to sludge input exhibits a largely proportional relationship as shown in Fig. 12.

\subsection{Scum generation characteristics}

As shown in Fig. 5, when the buoyancy associated with gas generation exceeds a threshold value, the organic sludge floats to the surface as scum. The relationship of the gas generation rate and the time from test start to scum generation is plotted in Fig. 11. Although there is a lot of scatter in the data, there is an inversely proportional trend. It is considered that scum develops when the total amount of anaerobic gas generated exceeds the gas retention capacity of the sludge, so it is necessary to consider the gas retention capacity of the sludge in regard to sludge rise.

In addition, the relationship of the risen scum thickness to sludge input exhibits a largely proportional relationship as shown in Fig. 12.

\section{CONCLUSION}

In this investigation, based on observations of scum generation during patrols of the Nomi River performed by the Ota City office, basic experiments were performed that simulated anaerobic gas and scum generation from temporary sedimentation of organic sludge associated with flooding. The main experimental findings are as follows:

- The generation of anaerobic gas started comparatively quickly after the water directly above the bottom mud became anaerobic, and a few hours later scum rapidly floated to the surface. In addition, after scum lost buoyancy and settled, gas was generated at a generally constant rate. The gas generation rate was by and large proportional to the sludge input.

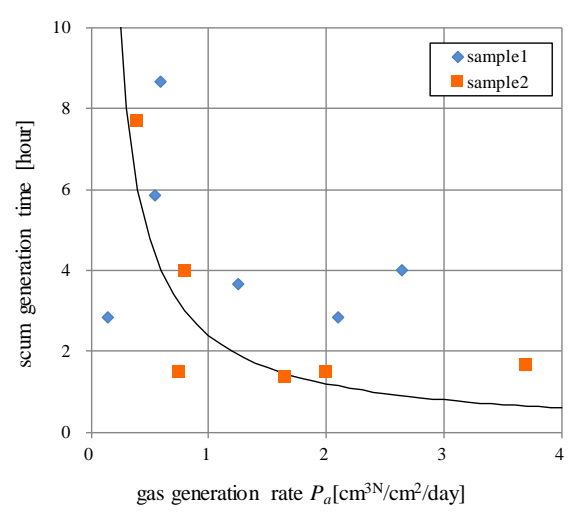

Figure 11: Relationship of gas generation rate to scum generation time.

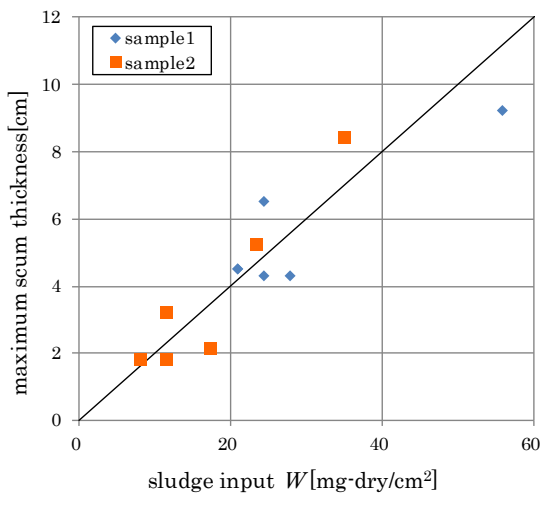

Figure 12: Relationship of sludge input to scum thickness. 
- The anaerobic gas generation rate increased rapidly with increased water temperature, and there was an approximately four-fold difference between $30^{\circ} \mathrm{C}$ and $20^{\circ} \mathrm{C}$. In addition, there was a negative correlation with salinity, and at salinities of $25 \%$ and higher the rate was almost zero.

- $\mathrm{CH}_{4}$ makes up approximately two-thirds of the anaerobic gas, followed by $\mathrm{CO}_{2}$. However, when salinity reaches $20 \%, \mathrm{H}_{2} \mathrm{~S}$ exceeds $\mathrm{CO}_{2}$. While the amount is not necessarily high, because $\mathrm{H}_{2} \mathrm{~S}$ is very poisonous and causes milky turbid water [2], it is thought to be important in environmental predictions and assessments of urban rivers.

- When anaerobic gas generation rates increased, scum developed quickly, and scum thickness was positively correlated with sludge input.

\section{ACKNOWLEDGEMENT}

The authors would like to thank the Ota City office, Tokyo Metropolitan Government for their support of the field survey and data collection.

\section{REFERENCES}

[1] Bureau of Sewerage Tokyo Metropolitan Government, Sewerage in Tokyo 2016, p. 9, 2016.

[2] Miura, S., Hotta, T., Negishi, H., Tsuruta, Y. \& Ishikawa, T., Modelling of colloidal sulfur in salinity-stratified urban streams. Proceedings of the 37th IAHR World Congress August 13 - 18, 2017, Kuala Lumpur, Malaysia, pp. 3442-3449, 2017.

[3] Yamazaki, M. \& Tsukui, K., Study on the Formation of Scum in Rivers. (1) Study on the origin of scum, Annual Report of the Tokyo Metropolitan Research Institute for Environmental Protection 1991, pp. 171-179, 1991.

[4] Yamazaki, M. \& Tsukui, K., Study on the Formation of Scum in Rivers. (2) Results of Investigation for Sedimental Conditions in Shiratoribashi-Iidabashi Area of Kanda River. Annual Report of the Tokyo Metropolitan Research Institute for Environmental Protection 1991-1992, pp. 182-184, 1991.

[5] Yamazaki, M. \& Tsukui, K., Study on the Production of Scum in Rivers. (3) Change in the Sediment Characteristics by a Rainfall. Annual Report of the Tokyo Metropolitan Research Institute for Environmental Protection 1992, pp. 167-171, 1992.

[6] Hamada, Y., Tanabe, H., Shimizu, N., Yoshioka, I., Mito, Y., Saitoh, T. \& Hibino, T., Designing of mud treatment method for sludge in cove using GCA. Journal of JSCE B3 (Ocean Engineering), 68(2), I_1151-I_1156, 2012.

[7] Hotta, T., Amano, M., Yamashita, Y., Chen, F.Y. \& Shoji, H., Observation on malodor gas generation in coastal area. Annual Journal of Coastal Engineering, JSCE, 49, pp. 1101-1105, 2002.

[8] Ushikubo, A., Takeshima, S. \& Takai, Y., Sulfate reducing and methane fermentation in a brackish water ecosystem: a modeling experiment. Bulletin of the Society of Sea Water Science, Japan, 47(1), pp. 19-23, 1993.

[9] Hanna, J.P., Brian, A.N. \& Patrick, J.M., Salinity influence on methane emissions from tidal marshes. Wetlands, 31, pp. 831-842., 2011.

[10] Schulz, H. \& Eder, B., Biogas-Praxis. Grundlagen, Planung, Anlagenbau, Beispiele, Ökobuch, 2001. 